\title{
Community Mapping and Theory of Planned Behavior as Study Tools for Solid Waste Management
}

\author{
Chainarong Apinhapath \\ Faculty of Public Health, Thammasat University, Rangsit Campus, Phaholyothin Road, Klongluang, Pathumthani 12121, Thailand \\ Correspondence should be addressed to Chainarong Apinhapath; ap_chai@hotmail.com
}

Received 12 May 2014; Revised 31 July 2014; Accepted 3 August 2014; Published 21 August 2014

Academic Editor: David Bolzonella

Copyright (C) 2014 Chainarong Apinhapath. This is an open access article distributed under the Creative Commons Attribution License, which permits unrestricted use, distribution, and reproduction in any medium, provided the original work is properly cited.

\begin{abstract}
Many cities have encountered problems with uncollected solid waste. Separate disposal of recyclable waste is viewed as the most effective procedure in waste management. However, this requires the cooperation of the people in the community. Community mapping is the most effective tool for understanding a community but it does not address possible ways to change people's behavior. The Theory of Planned Behavior was the basis for this study of recycling behavior as it offers methods for changing people's habits. However, the theory does not provide guidance on how to facilitate the use of recycling bins in the community. Many recycling projects have been unsuccessfully implemented due to the fact that most people do not want waste bins placed near their houses. Therefore, both of these effective tools were combined in this study, which propose an effective implementation method for community solid waste management.
\end{abstract}

\section{Introduction}

Municipal solid waste management has become a challenging environmental problem. Many cities in both urban and rural areas have encountered problems with disposal and treatment facilities that are inadequate to deal with the significant volume of solid waste. In Thailand, it is estimated that around 24.73 million tons of municipal solid waste was generated in the year 2012. Only $15.90 \mathrm{~m}$ tons $(64.29 \%)$ was disposed of in prepared waste bins and $11.90 \mathrm{~m}$ tons was collected. Therefore, more than half of the waste $(13.62 \mathrm{~m}$ tons or $55.08 \%)$ was untreated or incorrectly treated [1]. It is very expensive to improve disposal and treatment facilities [2]. Thus, the budgets for municipal solid waste management are insufficient to provide disposal facilities. Many cities confront objections from the community due to concerns about environmental conservation. Thus, new treatment plants, both sanitary landfills and incineration, have been banned in many municipalities.

Recycling is considered an effective measure to reduce the cost of collection, transportation, and treatment of waste $[2$, 3]. It also extends the life of sanitary landfills or incinerators for solid waste treatment and creates income for those who recycle.

Recycling behavior is defined as separating waste in specific waste bins or collecting behavior waste materials for selling to recycling shops. These recyclable materials will then be collected for processing into new products. This solid waste includes paper, glasses, plastics, and metals, that is, iron, copper, aluminum, and lead. However, in order to develop an effective program promoting recycling behavior, we need to know people's intention to recycle.

Many studies confirmed that intention is significant predictor of recycling behavior as suggested by the theory of planned behavior [4-10]. The theory also states that there are three factors influencing people's intention to recycling behavior: attitude, subjective norms, and perceive behavioral control. However, previous studies have shown inconsistent results [6, 9-17].

Prasatthong Sub-district Municipality, Ayutthaya, Thailand, has encountered an increasing amount of solid waste, from nine tons.day ${ }^{-1}$ in 2008 to 10 tons $\cdot \mathrm{day}^{-1}$ in 2009 and 2010, 11 tons $\cdot \mathrm{day}^{-1}$ in 2011, and 11.5 tons $\cdot \mathrm{day}^{-1}$ in 2012. At present, some solid waste is not collected on time. Since the 
municipality has a limited budget, staffs, and facilities, collection is done three days a week. To solve this problem, separation of recyclable materials has been proposed. Although the municipality plans to promote recycling behavior to all people, no promotional program has been developed as of yet.

Rong-J community was selected by purposive random sampling as the study area for developing a program. We needed to know the community's information, the present solid waste management in the community, people's intention to recycle, and factors influencing recycling behavior. Therefore, this study intended to survey community information, the present state of solid waste management in the community, people's intention to recycle, and factors associated with the intention to recycle.

\section{Materials and Methods}

Rong-J community was selected through random sampling of Prasatthong Sub-district Municipality. The community mapping technique was used in the information survey. Information on the current solid waste management in the community was obtained by interviewing some of the existing population and then cross-checking in interviews with the municipality's staff.

This community consisted of 57 households. Three hundred and one people from all the households were surveyed with a set of paper-based self-administered questionnaires. The questionnaire consisted of 18 direct questions about separate waste disposal, which was developed using the theory of planned behavior questionnaire format $[18,19]$. The questions sought information on intention, attitude, subjective norms, and perceived behavioral control in regard to the separate disposal of recyclable waste into specific waste bins as well as recommendations for future intervention on disposal behavior. A seven-point "agree-disagree" scale was used to measure intention, subjective norms, and perceived behavioral control. Bipolar adjectives in the seven-point scale were used to measure attitudes. The second part consisted of seven sociodemographic questions on sex, age, education, income, marital status, and position in family. These were multiplechoices or fill-in-the blank questions. The questionnaire was pilot tested with 20 people. Cronbach's alpha coefficient was used to measure validity; it was determined to be $0.851,0.726$, 0.750 , and 0.718 for intention, attitude, subjective norms, and perceived behavioral control, respectively.

The average scores of intention, attitude, subjective norms, and perceived behavioral control were calculated from the completed questionnaires. The factors associated with intention to separately dispose of recyclable waste were analyzed by stepwise multiple regression.

\section{Results and Discussion}

3.1. Community Information. The community was established by a group of people from other provinces who relocated to work in the nearby Rojana industrial estate. They rented some properties from a private owner. Later, their relatives were persuaded to come and stay nearby; therefore, the community grew. At present, the community is registered as Rong-J community for social, economic, governmental, environmental, and health development by law. Since this area is flooded in the rainy season every year, a long (752 meters) elevated narrow concrete footpath that connects every household in the community was constructed by the municipality (Figures 1 and 2). This footpath is wide enough for only two persons to walk side by side.

Most of the houses were constructed using concrete pillars, wood structures, ceiling tile walls, and zinc metal roofs. In general, the houses have only one floor with an open space underneath, similar to most Thai houses in the central plains area of Thailand where flooding happens every year (Figure 3).

A community map was drawn as shown in Figure 1. The map shows that the community is located between 3309 road and a small canal, a branch of the Chao Phraya River, Bang Pa-in district, PhraNakhon Si Ayutthaya Province, Thailand. The distance between the road and canal is around 250 meters. There are 57 households in the community. After the flooding that inundated the central plains of Thailand in 2011, many people in the community who work in nearby industries left to work in other provinces. Therefore, 18 households were vacant at the time of the study. The total registered population in the community as reported by the municipality was 301 people, but this was not likely an accurate figure. Based on interviews with some people in the community, it was estimated that the remaining population was only around 150 people. Beside the people who worked in industry, there were some merchants who owned grocery stores or restaurants in the community, as well as students. There were three groceries, two restaurants, and one barbershop in the community. In general, the elderly and women who did not work stayed at home during the day. The rest worked during daytime hours except those who worked the night shifts. All of the children went to school and were only at home for holidays. There is water supply to every house in the community.

3.2. Present Solid Waste Management. Solid waste, that is, plastic bags, snack bags, food containers made from plastic and foam, and plastic (both polyethylene and polyethylene terephthalate, PET) drinking water bottles can be easily observed on the ground in the community, in addition to private areas nearby that are separated by a wire net fence (Figures 4 and 5). Some houses have accumulated wooden pallets for renovating their homes. Each home has a waste bin and disposes of trash without separating it except for recyclable materials that can be sold such as paper, some kinds of plastic, and metals. The people must collect and transport solid waste by walking on the narrow footpath without cover from their homes to the municipal waste bin, which is located on 3309 road opposite the community entrance. Solid waste is generally collected by the municipal solid waste truck once a week. The people in the community often complain to the municipality about the difficulty encountered during transporting the waste due to the long distance. The situation 


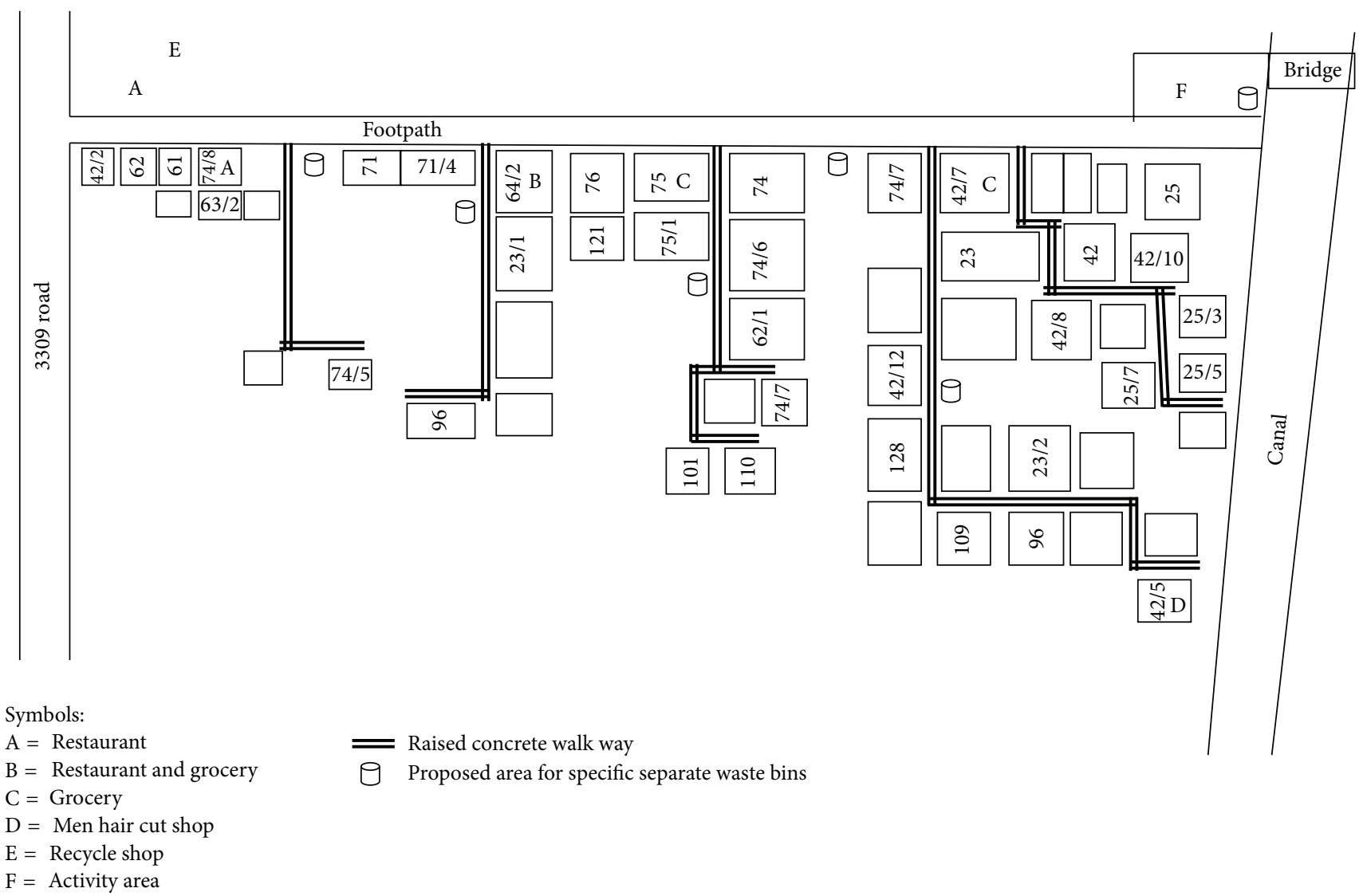

Figure 1: Map drawn from the study community: the blocks with numbers are houses with current occupants and the vacant blocks are deserted houses.

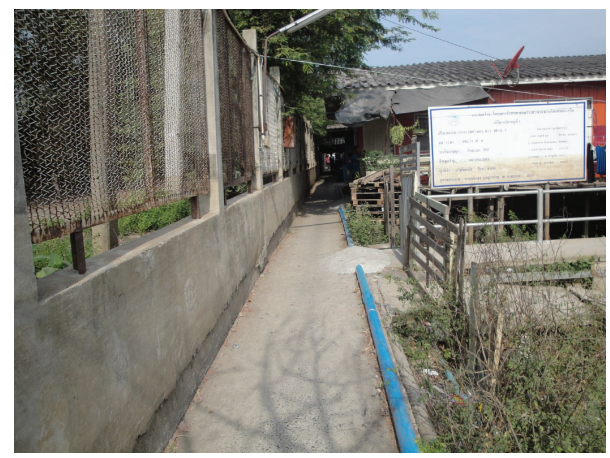

FIGURE 2: The elevated narrow concrete footpath in the community with a water supply pipe (blue line).

remains the same at current. One resident uses a space near the entrance of the community as a recycling shop; however, he buys only valuable recyclable materials, that is, paper, metals, and some kinds of plastic.

When asked about their requirements, all the interviewees felt that the municipality should distribute waste bins around the community area so they do not have to walk a long distance to dispose of solid waste. However, the locations of waste bins should not be close to households. The municipality should also collect solid waste more frequently, not only once a week.

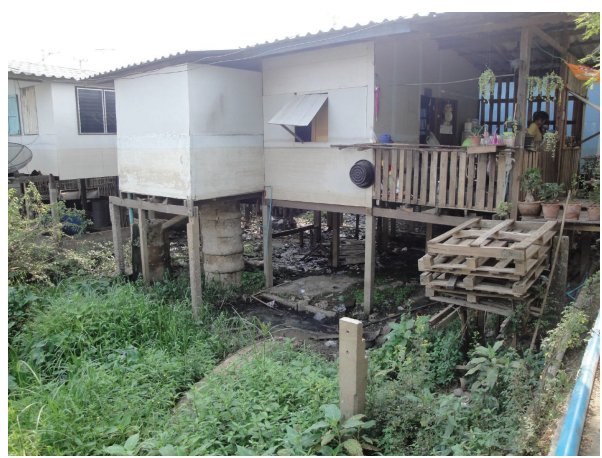

Figure 3: A house in the community constructed from concrete pillars, wood structures, ceiling tile walls, and a zinc metal roof.

When asked about separate disposal of recyclable wastes into specific waste bins, most of them agreed with this idea since they generally collect some valuable waste for sale such as paper boxes, glass bottles, and some kinds of plastics. It would be better if there were a merchant to buy their recyclable material for a high price and at a regular interval such as once or twice a month.

In addition, the concept of a recycling bank was proposed to all the interviewees. While most of them said it should be possible, some did not have an opinion about this concept. 


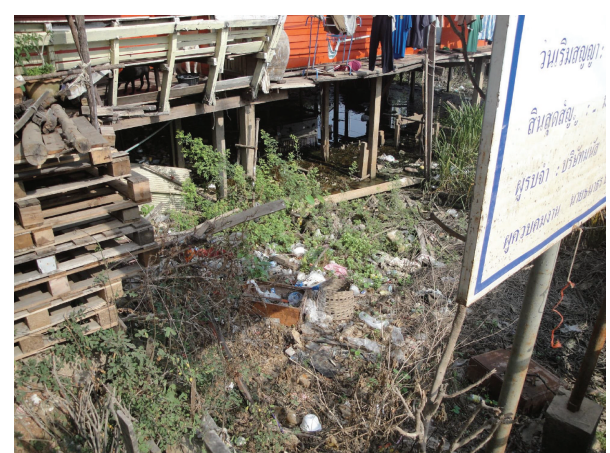

FIGURE 4: Solid waste found on the ground in the community.

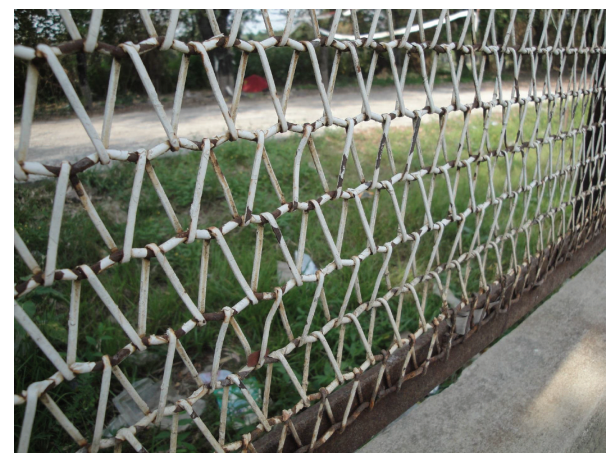

FIGURE 5: Solid waste in a nearby private area separated by a wire net fence.

The results from the interviews indicated that a recycling program is possible in the community. However, some remaining waste would still have to be managed after recycling such as perishable waste, bulky plastics, and packages that are compounds of more than one material. Perishable waste could be composted and used as fertilizer, while bulky plastics and consumer packaging should be collected and incinerated by the municipality.

3.3. People's Intention to Recycle. Thirty-one point eight percent of questionnaires were returned. Of those, 93.8 percent were completed. Most people were adult females (66.7\%)20 to 60 years of age. Forty percent had finished primary school and $40.5 \%$ were unemployed. Most of them (85.9\%) had income of less than 10,000 baht per month. More than half were married.

Around three-quarters (77.8\%) highly intended to dispose of recyclable waste into separate specific waste bins. Twelve point two percent had a moderate intention while only $10.0 \%$ had a low intention to dispose of recyclable materials into separate waste bins. Nearly all of them (92.2\%) showed a good attitude to separately dispose of recyclable materials while $5.6 \%$ showed a moderate attitude and only $2.2 \%$ showed a bad attitude. Nearly three-quarters $(73.3 \%)$ presented good subjective norms to separately dispose of recyclable materials while about a quarter $(24.4 \%)$ presented moderate subjective norms and only 2.2 presented bad subjective norms. The majority $(87.8 \%)$ had high perceived behavioral control to separately dispose of recyclable materials while only $4.4 \%$ and $7.8 \%$ had moderate and low perceived behavioral control, respectively.

The means of intention, attitude, subjective norms, and perceived behavioral control were high. This suggests that the people intended to dispose of recyclable materials in a separate specific waste bin. However, there was no specific waste bin in the community. Therefore, facilities especially specific separate waste bins should be provided to the community. In addition, a campaign to promote separate disposal of recyclable materials should be launched.

3.4. Factors Associated with Intention to Recycle Behavior. The relationship among all the study variables was analyzed by correlation (Table 1). All the variables showed a positive relationship with a rather low Pearson correlation coefficient value, which was significant at the 0.05 and 0.01 levels. According to the theory of planned behavior, if people evaluate a suggested behavior as positive (attitude); if they think their significant others want them to perform the behavior (subjective norm); and if they believe that they can perform the behavior (perceived behavioral control), this results in a higher intention (motivations) and they are more likely to engage in the behavior. A high correlation of attitudes, subjective norms, and perceived behavioral control to behavioral intention, and subsequently to behavior, has been confirmed in many studies $[5,8,20]$.

The regression analysis of the intention to separately dispose of recyclable waste demonstrated that all constructs of the theory of planned behavior-attitude, subjective norms, and perceived behavioral control-were factors associated with intention (Table 2).

The results from multiple regression analysis supported the applicability of the theory of planned behavior to understanding intention concerning the separate disposal of recyclable materials into a specific waste bin. The relationships among attitudes, subjective norms, and perceived behavioral control and intention were statistically significant. This suggests that those constructs are important factors of the intention to separately dispose of recyclable materials into a specific waste bin [19]. These three components explained $53.8 \%$ of the variance in recycling intention.

As no separate waste bins were found in the community, they should be made available for recyclable materials disposal around the community. We also found subjective norms, perceived behavioral control, and attitudes to be associated with the intention to dispose of recyclable waste into separate waste bins. Any method that can change these determinants could be applied to change people's behavior. These methods include, for example, persuasive communication, active learning, feedback, facilitation, modeling, and so forth. However, these constructs are founded on beliefs [21]. Therefore, any methods that can change beliefs could be applied to change these determinants [22]. Fishbein and Ajzen [21] recommended persuasive communication as the most suitable method since it is simple and cheap. However, a combination of methods is more likely than a single method to have a behavioral effect. Therefore, methods that can 


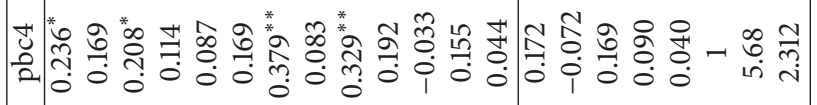

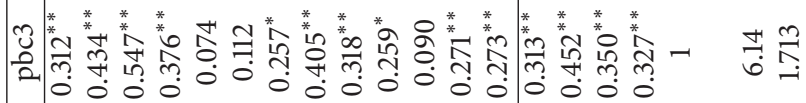

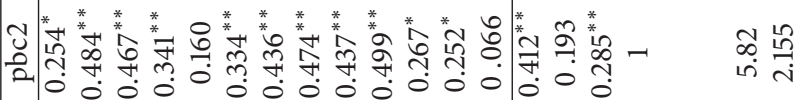

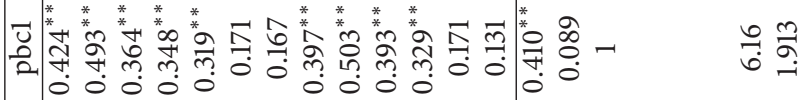

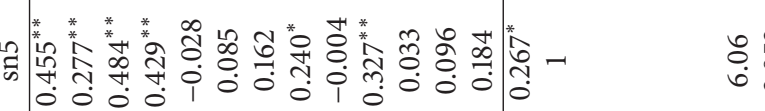

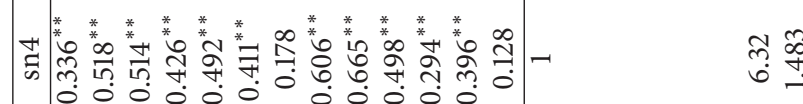

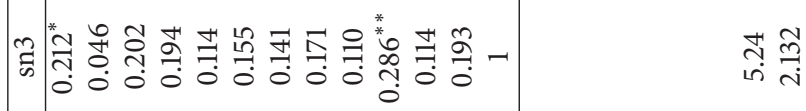

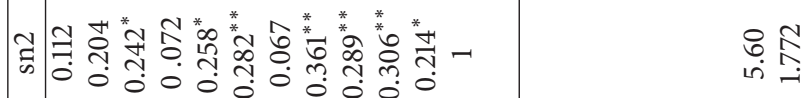

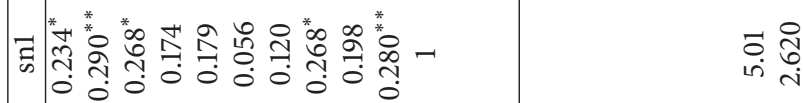

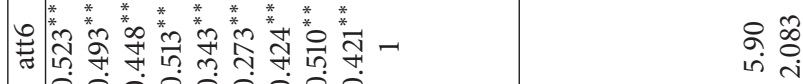

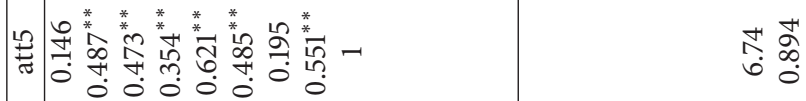

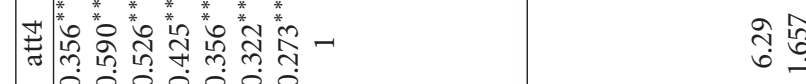

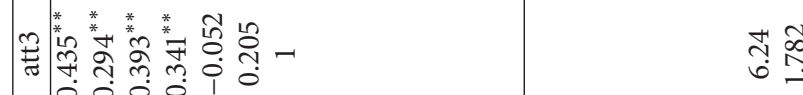

I气

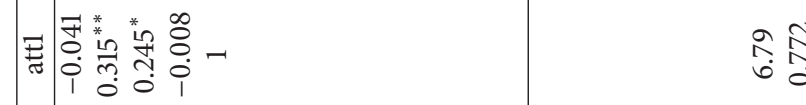

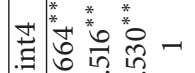

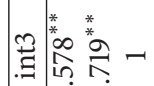

:

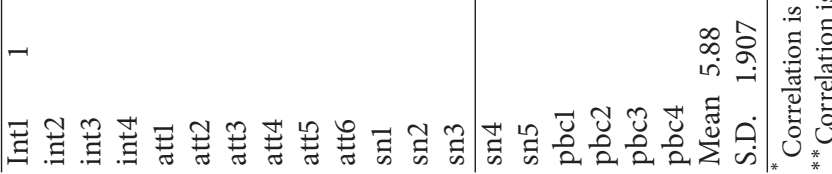


TABLE 2: Stepwise multiple regression analysis of the intention to separately dispose of recyclable waste.

\begin{tabular}{lccc}
\hline Variables & $B$ & S.E. & $P$ value \\
\hline Constant & -1.520 & 0.815 & 0.066 \\
Perceived behavioral & 0.403 & 0.120 & 0.001 \\
control & 0.504 & 0.175 & 0.003 \\
Attitude & 0.272 & 0.133 & 0.045 \\
\hline Subjective norms & 0.538 & & \\
\hline$R^{2}$ & & & \\
\hline
\end{tabular}

change attitudes, subjective norms, and perceived behavioral control should be selected for use in combination with the above methods for designing an effective intervention, for example, feedback, modeling, commitment, and motivation [22].

\section{Conclusions}

Although there were no specific separate waste bins, there is space to place them in the community. Rong-J community people's intentions, attitudes, subjective norms, and perceived behavioral control in regard to separate disposal of recyclable materials were high. Attitudes, subjective norms, and perceived behavioral control were associated with the intention to dispose of recyclable materials in separate waste bins. It is recommended that separate specific waste bins be made available for recyclable materials disposal around the community. A campaign to promote separate disposal of recyclable materials could be designed using a combination of methods such as persuasive communication, active learning, and others.

\section{Proposed Program}

Based on the fact finding, we propose a program to promote recycling behavior. The program should include the following: (1) municipality staff, people in the community, and academic staff, who should participate in establishing, launching, operating, and evaluating the program; (2) a recycling bank, which should be established and operated by the community with technical support from the academic staff and municipality; (3) the municipality should coordinate with private recycling shops to facilitate regular buying of recycled materials from the recycling bank; (4) the municipality should provide space, buildings, and facilities for the operation of the recycling bank; and (5) a big cleaning day should be launched by the community with the support of the municipality upon establishment of the program.

\section{Conflict of Interests}

The author declares that there is no conflict of interests regarding the publication of this paper.

\section{Acknowledgments}

This work was supported by the National Research University Project of the Thailand Office of the Higher Education Commission. Appreciation must be expressed to Assistant Professor Dr. Chanuantong Tanasugarn, Department of Health Education and Behavioral Science, Faculty of Public Health, Mahidol University, for her valuable suggestion.

\section{References}

[1] C. Trachu, Thailand Pollution Situation Report 2012, Department of Pollution Control, Bangkok, Thailand, 2012.

[2] S. Duffy and M. Verges, "It matters a hole lot: perceptual affordances of waste containers influence recycling compliance," Environment and Behavior, vol. 41, no. 5, pp. 741-749, 2009.

[3] L. I. Xuan, D. Baotong, and Y. E. Hua, "The research based on the 3-R principle of agro-circular economy model-the Erhai Lake Basin as an example," Energy Procedia, vol. 5, pp. 13991404,2011

[4] S. Barr, "Factors influencing environmental attitudes and behaviors: a U.K. case study of household waste management," Environment and Behavior, vol. 39, no. 4, pp. 435-473, 2007.

[5] G. Davis, P. S. Phillips, A. D. Read, and Y. Iida, "Demonstrating the need for the development of internal research capacity: Understanding recycling participation using the Theory of Planned Behaviour in West Oxfordshire, UK," Resources, Conservation and Recycling, vol. 46, no. 2, pp. 115-127, 2006.

[6] C. Knussen, F. Yule, J. MacKenzie, and M. Wells, "An analysis of intentions to recycle household waste: the roles of past behaviour, perceived habit, and perceived lack of facilities," Journal of Environmental Psychology, vol. 24, no. 2, pp. 237-246, 2004.

[7] J. P. Ogle, K. H. Hyllegard, and B. H. Dunbar, "Predicting patronage behaviors in a sustainable retail environment: adding retail characteristics and consumer lifestyle orientation to the belief-attitude-behavior intention model," Environment and Behavior, vol. 36, no. 5, pp. 717-741, 2004.

[8] L. Mannetti, A. Pierro, and S. Livi, "Recycling: planned and selfexpressive behaviour," Journal of Environmental Psychology, vol. 24, no. 2, pp. 227-236, 2004.

[9] M. Tonglet, P. S. Phillips, and M. P. Bates, "Determining the drivers for householder pro-environmental behaviour: waste minimisation compared to recycling," Resources, Conservation and Recycling, vol. 42, no. 1, pp. 27-48, 2004.

[10] M. Tonglet, P. S. Phillips, and A. D. Read, "Using the Theory of Planned Behaviour to investigate the determinants of recycling behaviour: a case study from Brixworth, UK," Resources, Conservation and Recycling, vol. 41, no. 3, pp. 191-214, 2004.

[11] R. Hansmann, P. Bernasconi, T. Smieszek, P. Loukopoulos, and R. W. Scholz, "Justifications and self-organization as determinants of recycling behavior: the case of used batteries," Resources, Conservation and Recycling, vol. 47, no. 2, pp. 133-159, 2006.

[12] T. L. Tudor, S. W. Barr, and A. W. Gilg, "A Novel conceptual framework for examining environmental behavior in large organizations: a case study of the Cornwall National Health Service (NHS) in the United Kingdom," Environment and Behavior, vol. 40, no. 3, pp. 426-450, 2008. 
[13] P. O. Do Valle, E. Reis, J. Menezes, and E. Rebelo, "Behavioral determinants of household recycling participation: the Portuguese case," Environment and Behavior, vol. 36, no. 4, pp. 505540, 2004.

[14] T. Kurz, M. Linden, and N. Sheehy, "Attitudinal and community influences on participation in new curbside recycling initiatives in Northern Ireland," Environment and Behavior, vol. 39, no. 3, pp. 367-391, 2007.

[15] T. C. Kelly, I. G. Mason, M. W. Leiss, and S. Ganesh, "University community responses to on-campus resource recycling," Resources, Conservation and Recycling, vol. 47, no. 1, pp. 42-55, 2006.

[16] M.-F. Chen and P.-J. Tung, “The moderating effect of perceived lack of facilities on consumers' recycling intentions," Environment and Behavior, vol. 42, no. 6, pp. 824-844, 2010.

[17] S. N. D. Mahmud and K. Osman, "The determinants of recycling intention behavior among the Malaysian school students: an application of Theory of Planned Behaviour," in Proceedings of the 1st World Conference on Learning, Teaching and Administration (WCLTA '10), pp. 119-124, October 2010.

[18] I. Ajzen, Constructing a TpB Questionnaire: Conceptual and Mathodological Considerations, 2006, http://people.umass.edu/ aizen/.

[19] J. J. Francis, M. P. Eccles, M. Johnston et al., Constructing Questionnaires Based on the Theory of Planned Behaviour: A Manual for Health Services Researchers, University of Newcastle, Newcastle, Australia, 2004.

[20] I. E. Berger, "The demographics of recycling and the structure of environmental behavior," Environment and Behavior, vol. 29, no. 4, pp. 515-531, 1997.

[21] M. Fishbein and I. Ajzen, Predicting and Changing Behavior: The Reasoned Action Approach, Psychology Press, New York, NY, USA, 2010.

[22] L. K. Bartholomew, G. S. Parcel, G. Kok, N. H. Gottlieb, and M. E. Fernandez, Planning Health Promotion Programs: An Intervention Mapping Approach, Jossey-Bass, San Francisco, Calif, USA, 2nd edition, 2006. 

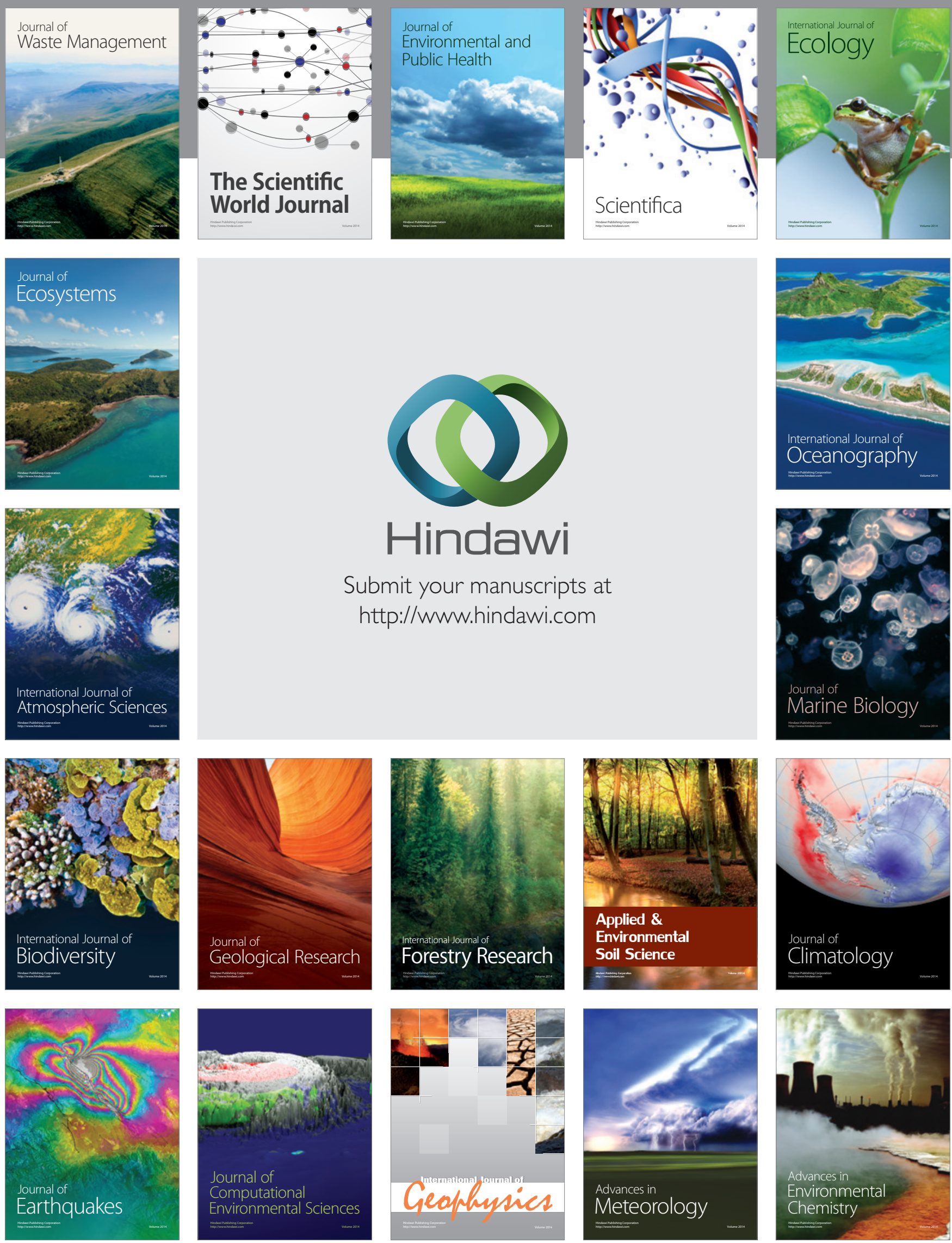